\title{
Cost Effectiveness of a School Dental Sealant Program for Access Improvement Among Children in Southern Thailand
}

\author{
Songchai Thitasomakul ${ }^{1}$ and Sukanya Tianviwat ${ }^{2}$ \\ ${ }^{1}$ Preventive Department, Faculty of Dentistry, Prince of Songkla University, Hatyai, Songkhla, 90110, Thailand. \\ ${ }^{2}$ Evidence-Based Dentistry for Oral Health Care and Promotion Research Unit, Preventive Department, Faculty of Dentistry, Prince \\ of Songkla University, Hatyai, Songkhla, 90110 Thailand.
}

\begin{abstract}
This study aimed to assess the cost effectiveness of a hospital-based dental clinic versus a mobile dental clinic for a school dental sealant program in southern Thailand. The expenditure approach was conventional and included labor costs, material costs and capital costs. Effectiveness was assessed as the number of caries-free teeth at six months after sealant in both types of clinic. One-way sensitivity analysis was performed based on the percentage of caries-free teeth at two years after program initiation. The results showed that the global cost-effectiveness ratio for a mobile dental clinic was less costly per caries-free tooth, while the incremental cost-effectiveness ratio was approximately 1.4 US dollars per caries-free tooth. The reasons to support decision making for added resources to bolster worth and effectiveness of a mobile dental clinic were opportunity costs of parents, prevalence of caries on occlusal and the inequity of oral health care among children in certain areas. In conclusion, the cost effectiveness existent in this circumstance makes the mobile dental clinic an interesting choice to increase children's accessibility to preventive dental service.
\end{abstract}

Keywords: Cost-effectiveness, Dental sealant, Caries prevention, Accessibility.

\section{INTRODUCTION}

Oral disease is a major health burden in many countries. The World Health Organization )2020( reported that approximately 3.58 billion people globally were affected in 2016 . Thailand also has a high prevalence of oral disease and dental caries, especially among children. The latest national oral health survey )Dental health division, 2017( reported that the prevalence of dental caries among 5-year-old children was $75.6 \%$, which was very high. Moreover, the result from the 2017 Health and Welfare survey by the National Statistical Office of Thailand )Tussanapirom et al., 2019( showed that only $7 \%$ of children aged less than 5 -years old and $18.1 \%$ of 6-12 year olds received dental treatment, which consisted mostly of receiving dental examination services. Even though Thailand has implemented a universal coverage scheme since 2002, the accessibility to and equity of oral health care remains a major problem )Tussanapirom et al., 2019 .

In order to alleviate dental caries in Thai children, the school dental sealant program recommended by the American Association of Community Dental Programs was launched in 1999 )Tianviwat et al., 2015(. However,

\footnotetext{
*Address correspondence to this author at Evidence-Based Dentistry for Oral Health Care and Promotion Research Unit, Preventive Department, Faculty of Dentistry, Prince of Songkla University, Hatyai, Songkhla, 90110 Thailand; Tel: 6674429875; E-mail: sukanya.ti@psu.ac.th
}

accessibility to dental sealants has generally been unsatisfactory since access to dental sealant service in hospitals is low. Therefore, a mobile service has been implemented at schools, whereby children can receive service directly at their schools, without the need for school absence. Mobile dental equipment was transported by van and temporary clinics were set up for 1-2 days at each school )Tianviwat, 2015(. In addition to increasing accessibility to dental service, the working conditions were also concerning because hospital-based care normally provides better conditions for working than a mobile dental unit, which is reflective of service effectiveness. Therefore, there was a need for an economic evaluation to gather evidence for decision making. Thus, the objective of this study was to evaluate the costeffectiveness and compare between hospital and mobile dental clinic for a school dental sealant program.

\section{MATERIALS AND METHODOLOGY}

The procedure for the cost-effectiveness analysis followed Drummond et al. )2005(. The conceptual model is presented in Fig. (1) and this study used a provider perspective. The methods described below are divided into two parts: cost and effectiveness of dental sealant between two types of dental sealant delivery approaches. The analysis included global cost-effectiveness ratio ) $\mathrm{C} / \mathrm{E}($, incremental cost-effectiveness ratio )ICER( and one-way sensitivity analysis. 


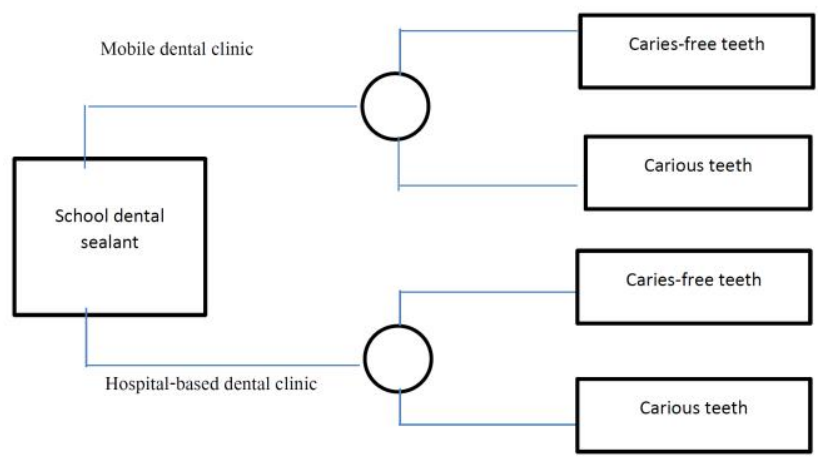

Fig. )1). Decision tree of a school dental sealant program for access improvement.

\section{Setting}

This study was carried out in a province in southern Thailand. There were 15 eligible contracting units for primary care )CUPs( in rural areas that administered sealants, involving either hospital-based or mobile )school-based( clinics. The target population comprised first-grade primary school children with an average age of 6-8 years. Sealant was delivered at the hospital-based clinic based on the referral of children to the hospital by parents or school teachers after being screened for sealant need at their school. The school-based services were carried out by mobile units visiting each of the schools within their area of responsibility for
1 or 2 days, as mentioned above. All the schools in the study operated an after-lunch tooth brushing program with fluoride toothpaste.

\section{Cost of Hospital and Mobile Dental Sealant}

The cost method was described elsewhere )Tianviwat, 2008(. In brief )Figure 2(, the conventional cost method was used and included labor costs )LC(, material costs )MC( and capital depreciation costs $) \mathrm{CC}$ (. Cost calculation was divided into two steps. First, the cost of each cost center, which was separated into two types including service cost centers and supportive cost centers, was calculated. There were six service cost centers and eight supportive cost centers. The costs from supportive cost centers were allocated into service cost centers weight by different criteria, i.e. the number of patients, amount of equipment and indirect costs. The full cost of each service cost center was the summation of direct costs and indirect costs. Subsequently, the full cost of the dental department was described as different dental services. Dental sealant cost, which was one type of dental service, was divided by the setting of service provided at a hospital and mobile clinic. The cost analysis was solved using Microsoft Excel 2013. In this study, the average cost per case based on Tianviwat )2008( was used to calculate the program cost for hospitals and mobile clinics.

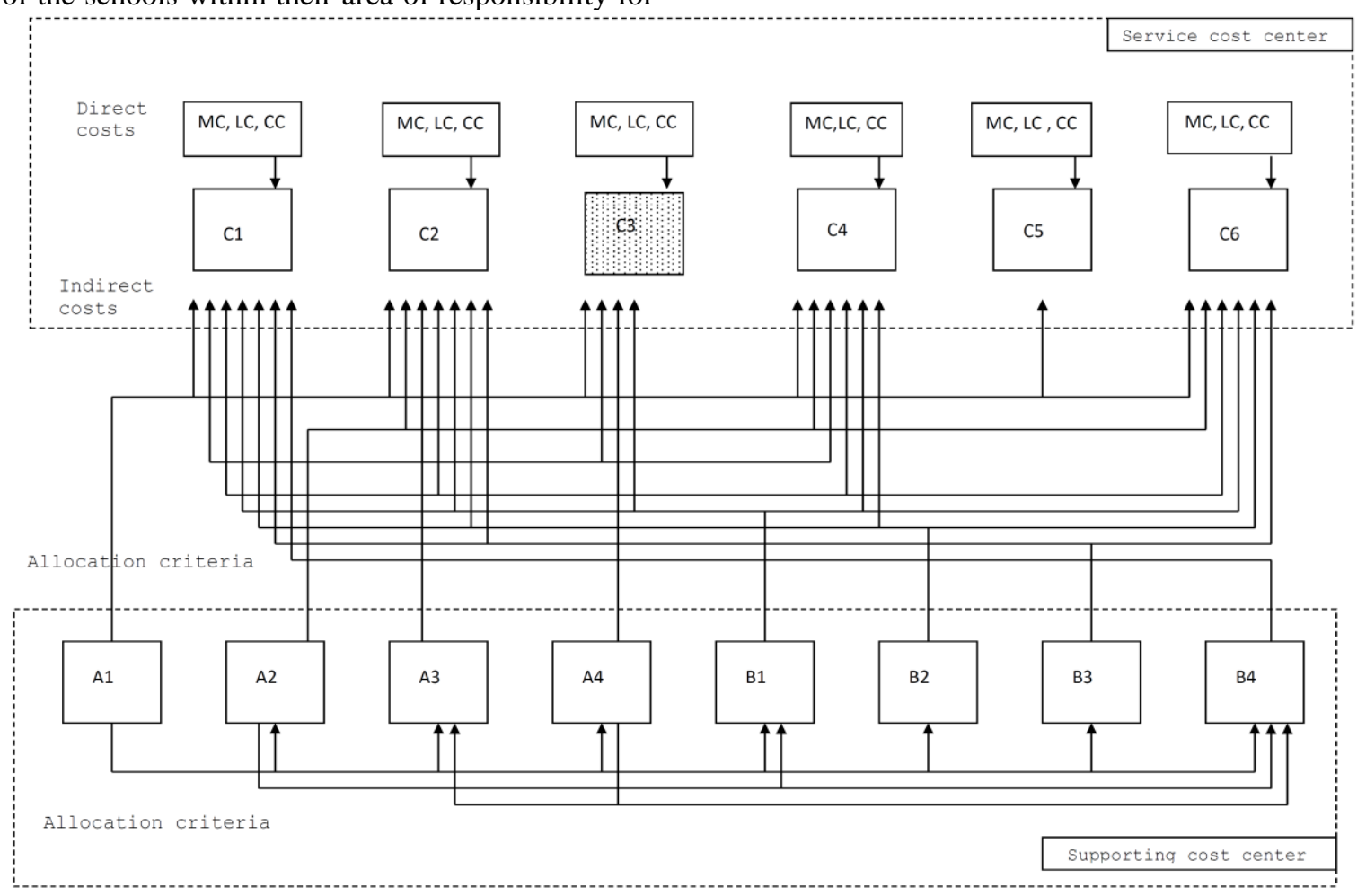

Fig. (2). Unit cost diagram for hospital services )See details in Annex(.

\section{Effectiveness of Hospital and Mobile Dental Sealant}

All sealant cases were handled by twelve CUPs (3 CUPs weer exchaned for safety reason), with a total number of 1703 school children and 4121 teeth. Caries-free first permanent molars with deep pit and fissure were chosen and light cure white sealant was used by experienced dental nurses. Application was performed according to the manufacturer's instructions. The caries detection criteria were discoloration of the occlusal surface and sticking with gentle probing )Tianviwat, 2008(. The effectiveness data comprised cariesfree teeth at 6 months after routine dental sealant application. 
This study involved baseline data for a larger project of audit and feedback for improving dental nurse performance )Tianviwat, 2015(. The quality control for examination was performed and presented as Kappa values for intra-examiner agreements between $0.80-0.85$, while inter-examiner agreement was 0.82 .

\section{Sensitivity Analysis}

The sensitivity analysis was done using the review of Tianviwat )2015( on caries after sealant in Thailand at a twoyear evaluation because the data was complete. There were six studies that covered two types of dental clinics and all studies launched a single application of sealant starting when children were about the same age )6-8 years old(. The review found that caries-free sealed teeth varied from 75.0 to $77.9 \%$ and from 67.4 to $85.5 \%$ for mobile dental clinics and hospital dental clinics, respectively )Thamtadawiwat, 2008; Obsuwan, 2008; Kongtawelert, 2008; Kantamaturapoj 2008; Thipsoonthornchai, 2003; Tianviwat, 2001(.

\section{Human Subject Approval Statement}

The research protocol was approved by the Ethics Committee of the Faculty of Dentistry, Prince of Songkla University )EC6207-021(.

\section{RESULT}

There were 2744 children with 4121 teeth; the measured effectiveness in terms of caries-free teeth after sealant was 2522 and 1427 teeth or $95.3 \%$ in mobile dental clinic and $96.8 \%$ in hospital-based dental clinic, respectively )Table $\mathbf{1}$ (. The details for costs are presented in Table $\mathbf{2}$. The majority of total costs in a mobile dental clinic were direct costs, whereas a hospital-based dental clinic involved indirect costs outside the department. Table $\mathbf{3}$ shows a higher global costeffectiveness ratio for a hospital-based dental clinic than a mobile dental clinic. The incremental cost per caries-free tooth was 44.4 baht or 1.4 US\$ )31.1 Thai baht per US\$, as of 30 October 2020(. Tables $\mathbf{4}$ and $\mathbf{5}$ present the data for oneway sensitivity analysis; the range of caries-free teeth across dental clinics )minimum and maximum percent(, scenarios derived from a combination of ranges. The sensitivity analysis is illustrated in Table $\mathbf{6}$, which shows the result of global cost-effectiveness ratio and ICER was a small change in the figures. Overall, the global cost-effectiveness ratio was higher in a hospital-based dental clinic than a mobile dental clinic in the base analysis )Table 3( as well as all scenarios in the sensitivity analysis )Table $\mathbf{6}$ (. The ICER ranged from 44.4 to 67.1 baht per caries-free tooth using a hospital-based dental clinic as the reference.

Table 1. Effectiveness of a School Sealant Program Under Different Settings.

\begin{tabular}{|c|c|c|}
\hline Choice of setting & Total $)$ teeth( & $\begin{array}{c}\text { Caries-free }) \text { teeth( } \\
) \%(\end{array}$ \\
\hline Mobile dental clinic & 2647 & $2522) 95.3($ \\
Hospital-based dental clinic & 1474 & $1427) 96.8($ \\
\hline Total & 4121 & $3949) 95.8($ \\
\hline
\end{tabular}

Table 2. Cost Category for a School Dental Sealant Program under Different Settings.

\begin{tabular}{|c|c|c|}
\hline Cost Category baht( & $\begin{array}{c}\text { Mobile } \\
\text { Dental Clinic }\end{array}$ & $\begin{array}{c}\text { Hospital-Based } \\
\text { Dental Clinic }\end{array}$ \\
\hline Direct cost & 163212 & 88882 \\
Labor cost & 107823 & 43849 \\
Material cost & 51942 & 29035 \\
Depreciation cost & 3447 & 15999 \\
Indirect cost & 82959 & 108634 \\
Within dental department & 23386 & 31998 \\
Outside dental department & 59573 & 76636 \\
\hline Total & 246,171 & 197,516 \\
\hline Average cost per tooth & 93 & 134 \\
\hline
\end{tabular}

Table 3. Incremental Cost Effectiveness Ratio )ICER( Compared Among Different Settings

\begin{tabular}{|c|c|c|c|c|}
\hline Setting & cost & effectiveness & Global C/E & ICER \\
\hline $\begin{array}{c}\text { Mobile dental } \\
\text { clinic }\end{array}$ & 246,171 & 2522 & 97.6 & 44.4 \\
\hline $\begin{array}{c}\text { Hospital-based } \\
\text { dental clinic }\end{array}$ & 197,516 & 1427 & 138.4 & - \\
\hline
\end{tabular}

Table 4. Sensitivity Analysis Scenario for Caries-Free Teeth after Sealant Combination Between Minimum and Maximum Percentage of Mobile Dental Clinic Versus Hospital Based Dental Clinic.

\begin{tabular}{|c|c|}
\hline Scenario & Combination of caries-free situations \\
\hline 1 & Mobile dental clinic )minimum( vs. Hospital-based clinic )minimum( \\
\hline 2 & Mobile dental clinic )minimum( vs. Hospital-based clinic )maximum( \\
\hline 3 & Mobile dental clinic )maximum( vs. Hospital-based clinic )minimum( \\
\hline 4 & Mobile dental clinic )maximum( vs. Hospital-based clinic )maximum( \\
\hline
\end{tabular}

Caries free of hospital minimum $=67.4 \%$, hospital maximum $=85.5 \%$ Caries free of mobile minimum $=75.0 \%$, mobile maximum $=77.9 \%$.

Table 5. Estimation of Caries-Free Teeth Based on Different Scenarios.

\begin{tabular}{|c|c|c|}
\hline Scenario & Mobile Dental Clinic $)$ Teeth( & Hospital-Based Clinic $)$ Teeth( \\
\hline 1 & $\frac{75.0}{100} \times 2647=1985$ & $\frac{67.4}{100} \times 1474=994$ \\
\hline 2 & $\frac{75.0}{100} \times 2647=1985$ & $\frac{85.5}{100} \times 1474=1260$ \\
\hline 3 & $\frac{77.9}{100} \times 2647=2062$ & $\frac{67.4}{100} \times 1474=994$ \\
\hline 4 & $\frac{77.9}{100} \times 2647=2062$ & $\frac{85.5}{100} \times 1474=1260$ \\
\hline
\end{tabular}


Table 6. One-Way Sensitivity Analysis of ICER Based on Different Scenarios

\begin{tabular}{|c|c|c|c|c|c|}
\hline $\begin{array}{c}\text { Sce- } \\
\text { nario }\end{array}$ & Setting & Cost & Effectiveness & $\begin{array}{c}\text { Global } \\
\text { C/E }\end{array}$ & $\begin{array}{c}\text { ICE } \\
\text { R }\end{array}$ \\
\hline 1 & $\begin{array}{c}\text { Mobile dental } \\
\text { clinic }\end{array}$ & 246,171 & 1985 & 124 & 49.1 \\
\hline 2 & $\begin{array}{c}\text { Hospital-based } \\
\text { dental clinic }\end{array}$ & 197,516 & 994 & 199 & - \\
\hline $\begin{array}{c}\text { Mobile dental } \\
\text { clinic }\end{array}$ & 246,171 & 1985 & 124 & 67.1 \\
\hline 3 & $\begin{array}{c}\text { Hospital-based } \\
\text { dental clinic }\end{array}$ & 197,516 & 1260 & 157 & - \\
\hline & $\begin{array}{c}\text { Mobile dental } \\
\text { clinic }\end{array}$ & 246,171 & 2062 & 119 & 45.6 \\
\hline 4 & $\begin{array}{c}\text { Hospital-based } \\
\text { dental clinic }\end{array}$ & 197,516 & 994 & 199 & - \\
\hline & $\begin{array}{c}\text { Mobile dental } \\
\text { clinic }\end{array}$ & 246,171 & 2062 & 119 & 60.7 \\
\hline & $\begin{array}{c}\text { Hospital-based } \\
\text { dental clinic }\end{array}$ & 197,516 & 1260 & 157 & - \\
\hline
\end{tabular}

\section{DISCUSSION}

The cost-effectiveness analysis found that the global costeffectiveness ratio was 97.6 baht and 138.4 baht per cariesfree tooth for mobile and hospital dental clinics, respectively. The choice of increasing access to dental service by mobile dental clinic used 44.4 baht or 1.4 US $\$$ per caries-free tooth at 6 months compared with the standard setting; hospital dental clinic. In this situation, the policy maker had to judge between the effectiveness derived versus the resources. The change of school sealant effectiveness from several studies of two-year evaluations concerning the sensitivity analysis consistently presented the same trend based on evidence.

According to Drummond et al. )2005(, the ICER in this study fell in quadrant 1 )Figure 3(, in which both cost and effectiveness were increased. To answer this question, Drummond suggested that the policy maker should answer the question "Is added effect worth added cost to adopt treatment?" The reasons supported a school sealant program via mobile dental clinic under some circumstances; opportunity cost of parents to accompany with children to hospital, prevalence of occlusal caries and equity to health care utilization. However, the balance between access to health service and quality of health care, i.e. sterilization and moisture control, should be considered as a hospital-based dental unit and equipment provide better visibility, moisture control and ergonomic positions for providers and assistants than a mobile dental clinic. Also, the sterilization system in a hospital is generally better than that in a mobile dental clinic.

The opportunity cost was one of the major reasons for insufficient oral health care )Tassanapirom, 2019(. Techakehakij )2013( studied direct non-medical cost for health care seekers at the out-patient department and found that the direct cost was 76.7 baht )2.5 US\$( to receive any health care service at a sub-district health-promoting hospital and 248.3 baht )8 US\$( to receive service at a hospital within the same district. Thus, cost savings from the parental perspective included the increased worth of the mobile dental clinic.

\begin{tabular}{|c|c|}
\hline \multicolumn{2}{|c|}{$\Delta$ cost } \\
\hline $\begin{array}{l}\text { Quadrant } 4 \\
\Delta \mathrm{C}>0, \Delta \mathrm{E}<0 \\
\text { Strong dominance for } \\
\text { decision making } \\
\text { (Reject) }\end{array}$ & $\begin{array}{l}\text { Quadrant } 1 \\
\Delta \mathrm{C}>0, \Delta \mathrm{E}>0 \\
\text { Is added effect worth added } \\
\text { cost to adopt treatment? }\end{array}$ \\
\hline $\begin{array}{l}\text { Quadrant } 3 \\
\Delta \mathrm{C}<0, \Delta \mathrm{E}<0\end{array}$ & $\begin{array}{l}\text { Quadrant } 2 \\
\Delta \mathrm{C}<0, \Delta \mathrm{E}>0\end{array}$ \\
\hline $\begin{array}{l}\text { Is reduced effect acceptable } \\
\text { given reduced cost to adopt } \\
\text { treatment? }\end{array}$ & $\begin{array}{l}\text { Dominance for decision } \\
\text { making } \\
\qquad \text { (Accept) }\end{array}$ \\
\hline
\end{tabular}

Fig. (3). Cost-effectiveness plane with four quadrants )adapted from Drummond, 2005.

The prevalence of occlusal caries was another reason to support the implementation of a mobile dental clinic where the inequity of oral health care was concerned. A study by Demirci )2010( showed that 52.7 to $66.3 \%$ of caries were found on the occlusal surface; this figure was increased among young children since the teeth are newly erupted. The most effective prevention program for occlusal caries was dental sealant )The Guide to Community Preventive Services, 2013(.

Supported by the scenario for the sensitivity analysis of twoyear effectiveness of the program, the ICER located in quadrant 1 )Figure 3( for both cost and effectiveness were increased. If the sealant remained, protecting and sealing the tooth at this age, the child had the ability for tooth brushing management as well as the ability to clean )Das, 2018 (. Therefore, the risk of caries would be reduced.

A benefit in this study was the high number of sealed children and sealed teeth. Further, the cost method was robust. However, the caries-free situation might be the result of a combination of dental sealant and tooth brushing with fluoride toothpaste after lunch, which was implemented among all children. Further study should include the services at primary health care providers because dental nurses currently allocate to the sub-district level to increase the accessibility of oral health services via a hospital-based unit.

\section{CONFLICT OF INTEREST STATEMENT}

The authors declare that they have no conflict of interest.

\section{REFERENCES}

Das, Usha Mohan, and Singhal, Parul.2009. "Tooth brushing skills for the children aged 3-11 years." Journal of Indian Society of Pedodontics and Preventive Dentistry 27.2: 104.

Dental Division.2017. The 8th Thailand National Oral Health survey report. Bangkok: Health Department )Thailand(, Ministry of Public Health.

Demirci, Mustafa, Safa Tuncer, and Ahmet Ayhan Yuceokur.2010. "Prevalence of caries on individual tooth surfaces and its distribution by age and gender in university clinic patients." European journal of dentistry 4.3: 270. 
Drummand MF, Sculpher MJ, Torrance Gw, O'Brien BJ, Stoddart GL. Methods for the economic evaluation of healthcare programmes. 3rd edition. New York: Oxford University Press; 2005.

Guide to Community Preventive Services. Preventing Dental Caries: School-Based Dental Sealant Delivery Programs. Retrieved August 3,2020 ) www.thecommunityguide.org/oral/caries.html(

Kantamaturapoj ,Kwanchai.2008.“The effectiveness of dental pit and fissure sealant program in primary school children in Kamphaengphet province.” Thailand Journal of Dental Public Health 12(2): 7-16.

Kongtawelert ,Prinya.2008. "A two-year evaluation of pit and fissure sealant of first permanent molars in school- based program )Yimsodsai Dekthaifundee( in Sukhothai province during 2005-2007." Thailand Journal of Dental Public Health 12(3): 86-96.

Obsuwan, Kosit. 2008. "The effectiveness of the pit and fissure sealant in the "Save our six" project Chiang Rai, Thailand." Thailand Journal of Dental Public Health 13)1(: 52-62.

Techakehakij, Win, Wongwichit, Piragit, Suksom Thirayut Burapatthananon ,Apichaya ,Yamkaew Watchalawalee, Pooltim, Kankanok ,Kaewwanich, Pathomporn ,Loytharn, Supida, Induang , Chaninat, Chitphet, Phatthamawadee and Tanamittramanee, Phatthamawadee.2013."Direct non-medical cost for health care seekers at the out-patient department: a cross-sectional survey." Journal of Health Systems Research 7)2(: 235-240.

Tianviwat ,Sukanya, Chukadee, Walee, Sirisakunweroj Banyen, Leewanant Rossukon, Larsen Morgen Joost.2001." Retention of pit and fissure sealants under field conditions after nearly 2-3 years". Journal of the Dental Association of Thailand 51(2): 115-120

Tianviwat, Sukanya, Chongsuvivatwong Virasakdi, Sirisakulveroj Banyen.2008."Loss of sealant retention and subsequent caries development." Community Dental Health 25(4): 216-220.
Tianviwat, Sukanya, Virasakdi Chongsuvivatwong, and Stephen Birch.2009. "Estimating unit costs for dental service delivery in institutional and community-based settings in Southern Thailand." Pp84-93 in Asia Pacific Journal of Public Health.Vol 21.

Tianviwat, Sukanya.2015. "Comparative School Dental Sealant Program to Alleviate Dental Caries Problem: Thai versus International Perspective" Pp. 165-90 in Emerging trends in oral health science and dentistry. 1st ed. Edited by Virdi MS. Rijeka: In-tech publication.

Thamtadawiwat, Decha.2008. "The effectiveness of dental pit and fissure sealant program for the student in Prathomsueksa 1 Cha-am district, Phetchaburi province." Thailand Journal of Dental Public Health 13)1(:25-36.

Thipsoonthornchai ,Jeerasak.2003. "The comparative study on retention rate and caries prevention between glass ionomer and resin using as pit and fissure sealant in mobile dental service, Buriram province." Thailand Journal of Dental Public Health 2 8(1-2): 62-77.

Tussanapirom, Teerawat, Panichkriangkrai, Warisa and Vongmongkol, Vuthiphan.2019. "Equity in Utilization of Oral Health Services among Thai Population: Results from Health and Welfare Survey 2017.” Journal of Health Systems Research 13)3(: 271-283.

World health organization. Oral health survey basic methods. Retrieved July 20,2013 http://apps.who.int/iris/bitstream/10665/97035/1/9789241548649 eng.pdf?ua $=1($

World health organization. Oral Health. Retrieved July 20, 2020 )https://www.who.int/health-topics/oral-health/\#tab=tab_1(

Copyright (C) 2020- All Rights Reserved

This is an open-access article. 